\title{
Exploring Factors Influencing the Use of an eHealth Intervention for Families of Children with Hearing Loss: An Application of the COM-B Model
}

Mansoureh Nickbakht, Ph.D. ${ }^{a *}$, Carly Meyer, Ph.D. ${ }^{\mathrm{a}, \mathrm{b}}$, Nerina Scarinci, Ph.D. ${ }^{\mathrm{a}, \mathrm{b}}$, and Rachael Beswick, Ph.D. ${ }^{\mathrm{c}}$

${ }^{a}$ School of Health and Rehabilitation Sciences, The University of Queensland, Brisbane, Australia; ${ }^{\mathrm{b}}$ The HEARing CRC, Melbourne, Australia; ${ }^{\mathrm{c}}$ Children's Health Queensland Hospital and Health Service, Healthy Hearing, Brisbane, Australia

Keywords: early intervention, hearing loss, family, eHealth, COM-B.

* Mansoureh Nickbakht (Corresponding author): School of Health and Rehabilitation Sciences, The University of Queensland, St. Lucia, Queensland, 4072, Australia.

Phone: +61 426746020 E-mail: mansoureh.nickbakht@ uqconnect.edu.au

ORCiD: $\underline{0000-0003-2936-4310}$

Carly Meyer: School of Health and Rehabilitation Sciences, The University of Queensland, St Lucia, Queensland, 4072, Australia.

Nerina Scarinci: School of Health and Rehabilitation Sciences, The University of Queensland, St Lucia, Queensland, 4072, Australia.

Rachael Beswick: Children's Health Queensland Hospital and Health Service, 10 Chapel St, Nundah, Queensland, 4012, Australia. 
Word count: abstract (250) body of the manuscript (3998)

Number of references: 40

Number of tables: 2 


\title{
Exploring Factors Influencing the Use of an eHealth Intervention for Families of Children with Hearing Loss: An Application of the COM-B Model
}

\begin{abstract}
Background: Prior to developing a successful eHealth intervention, it is important that we explore stakeholders' capacity to adapt to eHealth.

Objective: To explore what factors influence the use eHealth services from the perspectives of families of children with hearing loss and professionals who support families as they transition into early intervention.

Methods: A qualitative study incorporating semi-structured in-depth interviews was conducted with families $(n=17)$ and professionals $(n=11)$. Interview topic guides were developed based on the COM-B model of behaviour change to explore barriers and facilitators related to capability, opportunity, and motivation.

Results: The COM-B model captured several factors that may influence the use eHealth interventions for families of children with hearing loss. The capability factors included computer literacy and familiarity with social media. The opportunity factors were access to online resources, reliable Internet, and affordable equipment. Professionals' and families' preferences and a culture of face-to-face services were also identified as barriers for using eHealth. The motivation factors included families' and professionals' confidence in using technology and beliefs that there were benefits (e.g., saving travel) associated with using eHealth services. In contrast, beliefs that eHealth may be difficult to set up and not able to replace in-person communication identified as barriers to families and professionals adopting eHealth interventions.
\end{abstract}


Conclusion: Findings of this study indicated that implementation of an eHealth intervention could be facilitated by addressing the barriers in stakeholders' capabilities, opportunities (e.g., equipment and social support), and motivation (e.g., negative beliefs about eHealth) before developing eHealth services.

Keywords: early intervention, hearing loss, family, eHealth, COM-B.

\section{Introduction}

Families may experience a range of unmet needs following their child's diagnosis of permanent hearing loss (HL). ${ }^{1-3}$ For example, families have reported experiencing delays in receiving early intervention (EI) services ${ }^{1}$ and lack of informational support needed to make informed decisions for their child and their family. ${ }^{4}$ A growing option in EI for meeting families' needs is the delivery of services through eHealth (i.e., the use of information and communication technologies for health). ${ }^{5}$

Although traditionally used to provide healthcare services at a distance, eHealth can have a broader application to EI for families and professionals. From a patient and family

perspective, eHealth can provide earlier access to services by: enabling virtual home visits; ${ }^{6-8}$ providing opportunities for engaging siblings, grandparents, and local professionals through videoconferencing; ${ }^{9}$ and improving family outcomes and satisfaction. ${ }^{10-12}$ From a professional perspective, eHealth can improve professionals' effectiveness and adherence to clinical guidelines ${ }^{13}$ as well as facilitating professional development by providing opportunities to connect with specialists and participate in online courses. ${ }^{14}$

In terms of meeting the needs of families, one of the critical periods of clinical service delivery in which eHealth can play a role, is the period from diagnosis of HL to enrolment in an EI program (e.g., auditory-verbal therapy). During this period, families require informational, professional, and peer support ${ }^{3}$ as they must make a number of complex 
decisions about their child's use of communication and hearing technology, as well as a number of practical decisions for their families. ${ }^{15}$ Delays in decision making for enrolment into EI programs have adverse impacts on the child, including delayed language acquisition ${ }^{16}$ and delayed social and emotional development. ${ }^{17}$ One way to meet families' needs for information and support is via eHealth interventions.

However, prior to the development of any eHealth interventions, we need to ensure the likelihood of success of the intervention by exploring the factors that may influence its adoption. ${ }^{13}$ This is especially pertinent with eHealth interventions, as due to the rapid pace of change in the digital environment, there could be many factors affecting whether an eHealth intervention is successful or not ${ }^{13}$ and identifying these factors is important to avoid failure. Providing high-quality healthcare at a lower cost, for example, is an important factor. ${ }^{18}$

Given that healthcare interventions require health professionals and their clients to change their behaviour, the Capability-Opportunity-Motivation Behaviour (COM-B) model has been recommended. ${ }^{19}$ The COM-B is increasingly being used as its components are effective in identifying the reasons behind behaviour change. In the COM-B model, capability refers to the ability to engage in the necessary physical processes and thoughts for a behaviour and moderates the influence of motivation on behaviour. Opportunity refers to factors in the social or physical environment of people that moderated the link between the motivation and behaviour. Motivation, finally, refers to unconscious emotions and conscious beliefs that drive behaviours. ${ }^{19}$ The COM-B can be used to explore families' and professionals' capabilities and motivations toward the Internet and technologies as well as the opportunities for implementing eHealth. In a recent systematic review of healthcare services, individuals' beliefs and knowledge have been shown to be major contributing factors to the uptake of eHealth interventions, acting as both barriers and facilitators. ${ }^{20}$ A negative attitude 
toward eHealth and a limited understanding of the benefits of applying the Internet and technology in health services are other factors that have been shown to lead to failure. ${ }^{20}$

The aim of this study was, therefore, to explore what factors influence the use of eHealth services from the perspectives of families of children with HL and professionals who support families as they transition into EI.

\section{Methods}

A qualitative study incorporating semi-structured in-depth interviews was conducted with families of children with HL and their support professionals to obtain in-depth responses

from the participants by focusing on their experiences about eHealth. ${ }^{21}$ The COM-B model of behaviour change was used to inform the qualitative interviews and analysis procedures. The COM-B model implies that people must have the capabilities, opportunities, and motivation to engage in a particular behaviour (e.g., using eHealth), ${ }^{13}$ and thus the COM-B framework was utilized as a means of informing what areas need to be the focus of an eHealth intervention.

\section{Participants}

This study involved two participant groups: (1) families of children with congenital HL; and (2) the professionals who support these families.

Families met the inclusion criteria if their child: received services from a Stategovernment funded hearing transition service, was aged under 3 years of age at the time of the study, and was diagnosed with permanent HL. Family members were not included/excluded on the basis of their own hearing status. Seventeen family members of 15 children with HL (6 to 30 months of age) agreed to participate in this study (see Table $1)$.

$<$ Table 1> 
Families were informed of the study by a recruitment letter that was sent by a hearing service. Recruitment of the participants continued until the theoretical saturation of data achieved indicated no new data was emerging from the interviews. ${ }^{22}$

The professionals satisfied the inclusion criteria if they had experience in supporting families during the period from diagnosis of HL to enrolment in EI. The professionals were advised of the study in a meeting with the researchers. Volunteer participants were provided with written and verbal information about the study prior to the interviews. No inducements were provided to encourage the participants. Eleven professionals (3 psychologists, 6 social workers, 1 nurse, and 1 public health worker) were recruited from one State in Australia. The professionals were all female and had between 0.5 and 10 years of experience in the hearing service at the time of the interviews (Mean $=4.50$ years; $\mathrm{SD}=3.14)$.

\section{Materials}

Three interview guides were developed for the current study, one for each participant group (parents, grandparents, and professionals), based on the COM-B components for using eHealth services. Two demographic questionnaires were also developed to collect background information about the professionals and families who participated in the study.

\section{Study procedures}

This study was conducted under the ethics approval of the Children's Health Services Human Research Ethics Committee and The University of Queensland's Human Research Ethics Committee. It conformed in all respects to the National Statement on Ethical Conduct in Human Research. ${ }^{23}$ All participants provided informed consent before participating in interviews with a female research assistant with a psychology background who was trained in qualitative interviewing and was unknown to the participants. Families' interviews ranged in duration from 22 to 71 minutes $(M=43.31$ minutes $)$, and the professional interviews ranged 
in duration from 37 to 65 minutes $(M=48.36$ minutes $)$. As this study formed part of a larger study exploring the needs of families of children with HL in the transition period between diagnosis and EI, in addition to responding to questions related to factors influencing the use of eHealth services, participants also responded to questions relating to other parts of this project. The interviews were audio-recorded and transcribed verbatim by a professional transcription service and reviewed by the first author for accuracy. Data collection occurred from July 2016 to August 2017.

\section{Data analysis}

The COM-B model was used to inform the deductive thematic analysis of the qualitative interview data. ${ }^{24,25}$ Deductive analysis was used to explore participants' capabilities (i.e., physical and psychological ability to use eHealth), motivations (i.e., automatic and reflective mechanisms that activate or inhibit the use of eHealth) and opportunities (i.e., physical and social environment that facilitate the use eHealth) toward using the Internet and technology for health purposes. ${ }^{19}$ The first author, an audiologist who was unknown to the participants, de-identified the interview data, read the transcripts for familiarisation with data and generated the initial codes. Considering the COM-B components as the predefined categories in deductive analysis in this study, she mapped the codes onto the COM-B components using NVivo (QSR International Pty Ltd, Version 11). As transcripts were coded under the COM-B categories, the codes which emerged were rechecked by second and third authors, both paediatric speech-language pathologists with experience in qualitative research, as a peer-checking method to ensure the consistency of the analysis. Minor differences of opinion regarding the analysis were discussed and resolved in meetings that involved the first three authors. 


\section{Results}

Analysis of the interview data identified a range of factors that may influence the uptake of an eHealth service for families of children with HL. Example quotes representing each category within the COM-B components are presented below from the perspective of both family members $[\mathrm{F}]$ and professionals $[\mathrm{P}]$ (see Table 2).

$<$ Table 2>

\section{Physical and psychological capability}

The researchers identified that all the family members and professionals who participated in this study had the physical capability for using eHealth. In terms of psychological capability, factors such as knowledge and skills of using computers, the Internet, and smartphones were identified as being influential for some participants.

All families and most professionals explained that they had the required knowledge, computer literacy, and skills for using eHealth services. However, five professionals expressed their concerns that eHealth is not "an easy thing to set up by the sounds of it" [P6]. In addition, two of the professionals reflected that they were not technologically savvy and reported that some families in their caseload had "never seen an email in their life" [P6], suggesting that psychological capability may be a barrier for these families.

\section{Physical opportunity}

The interview data indicated that physical hardware (e.g., computers), informative DVDs, online resources (e.g., Applications), and Internet access were available for most families. Interestingly, some families reported that they did not have access to a DVD player but used computers instead. However, families in this study had a smartphone or home phone that could be used to receive eHealth services from the professionals or their peers. A loan scheme for iPads and language resources was also available in the current service. The iPad 
could be used for videoconferencing with the health professionals or teaching language to the child. In addition, some DVDs were available to inform parents about their child's communication needs and about the role of different professionals.

However, a lack of access to relevant online resources was reported by a mother. She suggested an online chat or online support service could be available to answer families' questions:

"If there's a support area online that, say if there's questions at any time of day, maybe put through a message request ... Where you just write down maybe something you wanted to talk about but maybe don't have time to speak on the phone to, you can probably get a response" [F12].

An App was also available to provide information to families about HL, audiograms, hearing technologies, professionals, and services. However, the App was reported by one mother to simply replicate information that is available elsewhere: "I downloaded an application... it was useless ... It's probably the same information of the DVD or similar" [F7]. A grandmother who participated in the interviews also identified a gap in available Apps to help grandparents communicate with their grandchild:

"If they had smart little Apps that helped us to play with [child] or communicate with [child], depending on how she goes with her implants and how her language skills develop and that kind of thing, that would be great" [F14].

A mother also suggested an App for peer support:

"Connections to other people, chat, and feedback. Access the services like questions and answers ... Just somewhere where someone can go to feel like they can relate to other parents" [F10]. 
In terms of the Internet, a lack of access to an acceptable Internet connection was identified as a barrier to eHealth by a few families and professionals. Two professionals also reported that the Internet may not be affordable for some families.

\section{Social opportunity}

The interview data suggested that the professionals had the social support of their peers to use an eHealth service as videoconferencing with families was currently "encouraged and accepted" in their office. It was not clear from the interviews; however, whether families had social opportunities to encourage them to use eHealth services. A professional connecting families to other families of children with HL to provide social support was one facilitator identified which may encourage families to adopt eHealth services: "The key to that one [acceptance of eHealth] is really to get a couple of families who use it [teleschool] and know that it actually works for them, and then have them connect" [P1].

A face-to-face culture within the current service was also reported by three professionals as influencing the uptake of eHealth services. Two professionals, therefore, expressed the need for ongoing training and professional development to not only upskill professionals in eHealth technologies but also to address a potential shift in culture: "They [clinics at hospitals] are still finding their way, I think. They need a lot of help to change the culture” [P6].

\section{Automatic motivation}

Desires and needs of the professionals and families may also influence the use of eHealth services. A professional expressed concern that families wanted services that were convenient: "they all want access to something that's convenient" [P3] and families reported that they were frequently using the technology and were dependent on their phones and social 
media. The interviews also showed that the professionals routinely phoned and emailed families.

However, one professional reported a contrasting view towards videoconferencing noting that "it doesn't come naturally" to her [P7]. Two mothers also reported that they did not regularly check their emails, primarily because they often "forget" or they had health concerns about regularly using a computer: "I hate looking at the computer ... It hurts my eyes" [F5].

\section{Reflective motivation}

Beliefs and preferences about using technologies can also influence the use of eHealth services. Most of the participants in this study reported that eHealth services are "inevitable" and can be "complementary" to services such as hospital appointments, counselling, and peer support to save families time, cost, and travelling to health services.

A mother and a professional also expressed their beliefs about the information available in the DVDs in the current service, noting that they believed that the DVDs could meet a different information need for parents, for example, helping parents to explain the HL to siblings:

"That [DVD] was good because I was able to play the video and then explain it to him [3.5-year-old sibling] that way. That was a good inclusion for people who already have kids" [F3].

A professional also reported that the DVDs could be used to help take the pressure off parents by involving siblings in communication with the child with HL:

"I say, just put it [DVD] on when you're making dinner ... it's great for the other kids to see it, so they can see, they can all be drawn in. So, takes focus on just mum doing everything which will put a lot of pressure on" [P6]. 
Although the above participant quotes indicated that their beliefs about eHealth may facilitate their use of eHealth services, some families and professionals held beliefs that may create barriers for using eHealth. For example, six professionals expressed a belief that videoconferencing cannot replace in-person services as building rapport and obtaining the nuances of verbal contacts might be missed when using technologies. A professional, therefore, suggested giving a choice to families for the mode of service delivery.

In addition to their beliefs, families reflected on their personal preferences for using technologies. Among different available technologies, phone calls were preferred over emails. One mother, however, reported that she preferred emails as she found it easier to receive information in this way, and a grandmother preferred emails for providing information to extended families.

Some professionals also expressed their personal preferences for using technologies as a professional said:

"It [technology] is not my preferred mode of communication. I don't Facebook in my life ... I find emailing families really helpful so that is something that from a technology perspective that I think really value adds, and text, the phone conferencing stuff" [P7].

The professionals also highlighted the importance of family and professional confidence in using eHealth services: "I think a family confidence in using technology is a really big barrier" [P3]. Finally, when we asked families what would motivate them to use technology to get support, one of them said: "Relevance and finding stuff interesting" [F4].

\section{Discussion}

This study explored factors that may influence the use of eHealth services from the perspectives of families of children with HL and professionals who support families as they transition into EI. The components of the COM-B model were used to classify the 
participants' perspectives. The capability factors included computer literacy and familiarity with social media. The opportunity factors were access to online resources, reliable Internet, and affordable equipment. Professionals' and families' preferences and a culture of face-toface services were also identified as barriers for using eHealth interventions. The motivation factors included families' and professionals' confidence in using technology and beliefs that there were benefits associated with using eHealth services, with beliefs that eHealth may be difficult to set up and not able to replace in-person communication identified as a barrier to families and professionals adopting eHealth interventions.

An important factor identified in the current study was confidence in using eHealth services that has been acknowledged as a major factor in adopting eHealth interventions. ${ }^{26}$ While other studies reported equal confidence for face-to-face and eHealth service provision by speech-pathologists ${ }^{27}$ and high acceptance for using online consultations, ${ }^{28}$ some professionals in the current study reported a preference for an in-person face-to-face service because they were more knowledgeable and confident practicing in an in-person mode; and it was the cultural norm in their workplace.

The professionals in the current study reported different cultures of using the Internet and technology. At one extreme, some of the professionals reported being very confident and routine users of technology, while at the other end, some of the professionals reported a strong preference for face-to-face in-person service delivery. This finding is similar to a mixed-methods study among rural Australian speech-language pathologists that showed some professionals were not willing to replace face-to-face appointments with eHealth. ${ }^{29}$ The study also indicated that rural clients had more positive attitudes towards speech-pathology services via technology than expected by professionals. Another Australian study also investigated audiology clients' attitudes to use eHealth for ear and hearing services and reported that a 
preference for face-to-face services was a barrier for eHealth appointments. ${ }^{30}$ The professionals in the current study suggested that in the context of support services for families, it might be the face-to-face culture which could serve as a barrier for implementing eHealth in hearing healthcare services. Given that previous literature has also identified a face-to-face culture associated with using eHealth services among professionals and clients ${ }^{29}$, ${ }^{30}$ and that cultural norms and social support could influence the uptake of the Internet and technology, ${ }^{19,31}$ the culture of both families and professionals needs to be investigated prior to commencing an eHealth service. ${ }^{32}$

Although strong motivation of some participants toward eHealth could facilitate an eHealth intervention in the current hearing service, half of the professionals and a grandparent in this study expressed their beliefs that eHealth services could not fully replace in-person services. The professionals had concerns that building rapport was not possible by videoconferencing as the nuances of non-verbal communication may be missing during online interactions. A feeling that non-verbal cues could be challenging even at higher bandwidths Internet has already been reported in a review of online doctor-patient communication $^{33}$ and in a study that explored the perspectives of American speech-language pathologists on eHealth service provision in school settings. ${ }^{34}$ Some Australian speechlanguage pathologists also reported a mixed feeling towards eHealth service provision (e.g., excitement about the eHealth potentials and uncertainty about the effectiveness of eHealth) and difficulties such as a need for more time and effort to establish relationships with families. $^{35}$

Access to suitable infrastructure was also identified as an important factor for eHealth implementation success. This finding corroborates the findings from recent reviews that suggested service providers must make sure families have access to a sufficient bandwidth 
prior to commencing an eHealth service. ${ }^{5,20}$ This preparation is essential in order to avoid challenges during videoconferencing and the subsequent dissatisfaction of families with eHealth interventions ${ }^{36}$ that could lead to failure of the intervention in the longer term. ${ }^{36,37}$ This study has important clinical implications for policymakers, service providers, and professionals. In order to implement eHealth into paediatric hearing support services, they should identify intervention functions and behaviour change techniques ${ }^{19}$ that specifically address the culture against eHealth services. It is important to consider intervention strategies that are likely to be most effective in addressing the relevant mechanisms of change. For example, intervention functions such as modeling and enablement have been suggested by West and Michie ${ }^{13}$ to address the culture against eHealth services. By modelling, the professionals will be provided with an example of successful implication of using the technology in hearing services by others to imitate or aspire to shape their way of thinking toward eHealth. By enablement professionals' capabilities will be increased via decreasing barriers or increasing means. ${ }^{19}$ Professionals, for instance, could be provided with practical guidelines for using technologies relevant to their role. Providing practical social support (i.e., advice or practical help from colleagues about using eHealth) would also be an appropriate behaviour change technique for enablement.

In addition, as capability can have a direct and explicit influence on people's motivation, ${ }^{13}$ professionals may need to obtain ongoing training in all aspects of eHealth interventions, including technical aspects and challenges to address the concerns related to building rapport with the clients and support transitioning to service provision via eHealth. ${ }^{35}$, ${ }^{38}$ It is also suggested that professionals rely more on verbal communication than non-verbal cues during online interactions. ${ }^{39} \mathrm{~A}$ study also suggested a balance between the use eHealth 
services and in-person services to address the concerns of professionals for building a relationship with their clients. ${ }^{40}$

Further, each family and professional interviewed in this study expressed their unique preferences for providing and receiving services, including using phone calls, email, personal visits, and written information. The different preferences highlighted in this study emphasizes the importance of exploring and considering the diversity among the receivers of the eHealth intervention to tailor the eHealth intervention to the target users, ${ }^{13}$ and importantly, providing individualized services to families that meet their individual needs and preferences.

\section{Limitations and future directions}

Applying the COM-B model and interviewing families from both metropolitan and regional areas, some who had English as a second language, helped us to comprehensively investigate a number of factors in eHealth users' capabilities, opportunities, and motivation that may influence the use eHealth intervention. However, only a small number of health professionals, mostly social workers and psychologists, participated in the current study. Further, the professionals spoke about families who did not have access to electricity or the Internet who did not participate in this study. Therefore, the identified contributing factors in this study may not be representative of all factors that might influence the use of eHealth services in hearing healthcare. In future studies, it is important to recruit a broader range of families of children with HL and more professionals from different disciplines. A further study is also recommended to develop family-centred Apps as a means for extended families to communicate with children with HL. Another App could also be developed to facilitate connecting families who have the same cultural background. In future investigations, a focus on changing the face-to-face culture is also needed. 


\section{Conclusion}

This study used the COM-B model of behaviour to identify the factors that may influence the use eHealth services by families of children with HL and their support professionals. The results suggest that eHealth is a viable option for providing early hearing support services to families of children with HL, and highlighted that implementation of an eHealth intervention could be facilitated by addressing the barriers in stakeholders' capabilities (e.g., knowledge), opportunities (e.g., social support to overcome face-to-face culture), and motivation (e.g., negative beliefs about eHealth) before developing an eHealth intervention.

\section{Declaration of interest}

The authors report no declarations of interest.

\section{Presentation}

Some parts of this study have been presented at a conference: Nickbakht, M., Meyer, C., Scarinci, N., \& Beswick, R. Barriers and facilitators to adopting telehealth within early hearing support services: A qualitative study using the COM-B model of behaviour change. Successes and Failures in Telehealth (SFT17). Oct 2017. Brisbane, Australia.

\section{Funding}

This research was supported by an Australian Government Research Training Program Scholarship. The authors acknowledge the financial support of the HEARing CRC, established under the Australian Government's Cooperative Research Centres (CRC) Program. The CRC Program supports industry-led collaborations between industry, researchers and the community. 


\section{Acknowledgment}

The authors would like to thank professionals and family members who participated in this study as well as Jenny Atkins who helped with conducting the interviews. 


\section{References}

1. Sjoblad S, Harrison M, Roush J, McWilliam R. Parents' reactions and recommendations after diagnosis and hearing aid fitting. Am J Audiol. 2001;10:24-31.

2. Gilliver M, Ching TYC, Sjahalam-King J. When expectation meets experience: Parents' recollections of and experiences with a child diagnosed with hearing loss soon after birth. Int J Audiol. 2013;52:S10-S16.

3. Nickbakht M, Meyer, C., Scarinci, N., \& Beswick, R. A Qualitative investigation of families' needs in the transition to early intervention after diagnosis of hearing loss. Child Care Health Dev. 2019;45:670-680.

4. Roberts RM, Sands F, Gannoni A, Marciano T. Perceptions of the support that mothers and fathers of children with cochlear implants receive in South Australia: A qualitative study. Int J Audiol. 2015;54:942-950.

5. McCarthy M, Leigh G, Arthur-Kelly M. Telepractice delivery of family-centred early intervention for children who are deaf or hard of hearing: A scoping review. J Telemed Telecare. 2018;25:249-260.

6. Stredler-Brown A, Houston KT, Alverson DC. More than 150 years in the making: The evolution of telepractice for hearing, speech, and language services. Volta Rev. $2012 ; 112: 195$

7. Hayes D, Boada K, Coe S. Early Hearing Detection and Intervention by Telepractice. SIG 18 Perspectives on Telepractice. 2015;5:38-47.

8. Olsen S, Fiechtl B, Rule S. An evaluation of virtual home visits in early intervention: Feasibility of virtual intervention. Volta Rev. 2012;112:267-281. 
9. McCarthy M, Muñoz K, White K. Teleintervention for infants and young children who are deaf or hard-of-hearing. Pediatrics. 2010;126:S52-S58.

10. Behl DD, Houston KT, Stredler-Brown A. The value of a learning community to support telepractice for infants and toddlers with hearing loss. Volta Rev. 2012;112:313.

11. Chi NC, Demiris G. A systematic review of telehealth tools and interventions to support family caregivers. J Telemed Telecare. 2015;21:37-44.

12. Davis A, Hopkins T, Abrahams Y. Maximizing the impact of telepractice through a multifaceted service delivery model at the Shepherd Centre, Australia. Volta Rev. $2012 ; 112: 383$.

13. West R, Michie S. A Guide to Development and Evaluation of Digital Behaviour Interventions in Healthcare. London, England: Silverback Publishing; 2016.

14. Moffatt JJ, Eley DS. The reported benefits of telehealth for rural Australians. Aust Health Rev. 2010;34:276-281.

15. Porter A, Creed P, Hood M, Ching TYC. Parental decision-making and deaf children: A systematic literature review. J Deaf Stud Deaf Educ. 2018:295-306.

16. Schick B, De Villiers P, De Villiers J, Hoffmeister R. Language and theory of mind: A study of deaf children. Child Dev. 2007;78:376-396.

17. Vogel-Walcutt JJ, Schatschneider C, Bowers C. Social-emotional functioning of elementary-age deaf children: A profile analysis. American Ann Deaf. 2011;156:6-22.

18. Granja C, Janssen W, Johansen MA. Factors determining the success and failure of eHealth interventions: Systematic review of the literature. J Med Internet Res. 2018;20:e10235. 
19. Michie S, Atkins L, West R. The Behaviour Change Wheel: A guide to designing interventions. Great Britain: Silverback Publishing; 2014.

20. Ross J, Stevenson F, Lau R, Murray E. Factors that influence the implementation of ehealth: A systematic review of systematic reviews (an update). Implement Sci. 2016;11:146.

21. Creswell JW. Research design: Qualitative, quantitative, and mixed methods approaches. 4 ed. California, CA: SAGE Publications; 2014.

22. Morse JM. The significance of saturation. Qual Health Res. 1995;5:147-149.

23. National Statement on Ethical Conduct in Human Research. The National Health and Medical Research Council, the Australian Research Council and the Australian ViceChancellors' Committee. Canberra: Commonwealth of Australia; 2007 Updated 2018.

24. Boyatzis RE. Transforming qualitative information: Thematic analysis and code development. California, CA: SAGE Publications; 1998.

25. Barker F, Atkins L, de Lusignan S. Applying the COM-B behaviour model and behaviour change wheel to develop an intervention to improve hearing-aid use in adult auditory rehabilitation. Int J Audiol. 2016;55:S90-S98.

26. Kope M. Understanding e-literacy. In: Martin A, Madigan D, eds. Digital Literacies for Learning. London, England: Facet; 2006:68-79.

27. Freckmann A, Hines M, Lincoln M. Clinicians' perspectives of therapeutic alliance in face-to-face and telepractice speech-language pathology sessions. Int J Speech Lang Pathol. 2017;19:287-296.

28. Liddy C, Drosinis P, Keely E. Electronic consultation systems: Worldwide prevalence and their impact on patient care-a systematic review. Fam Prac. 2016;33:274-285. 
29. Dunkley C, Pattie L, Wilson L, McAllister L. A comparison of rural speech-language pathologists' and residents' access to and attitudes towards the use of technology for speech-language pathology service delivery. Int J Speech Lang Pathol. 2010;12:333-343.

30. Eikelboom RH, Atlas MD. Attitude to telemedicine, and willingness to use it, in audiology patients. $J$ Telemed Telecare. 2005;11:22-25.

31. Mandirola Brieux HF, Bhuiyan Masud JH, Kumar Meher S, et al. Challenges and Hurdles of eHealth Implementation in Developing Countries. Stud Health Technol Inform. $2015 ; 216: 434-437$.

32. Lindholm C, Erlingsdóttir G. eHealth and the medical profession. In: Erlingsdóttir G, Sandberg H, eds. eHealth opportunities and challenges: a white paper. Lund, Sweden: Lund University; 2016.

33. Miller EA. Telemedicine and doctor-patient communication: an analytical survey of the literature. $J$ Telemed Telecare. 2001;7:1-17.

34. Tucker JK. Perspectives of speech-language pathologists on the use of telepractice in schools: Quantitative survey results. Int J Telerehabil. 2012;4:61-72.

35. Hines M, Lincoln M, Ramsden R, Martinovich J, Fairweather C. Speech pathologists' perspectives on transitioning to telepractice: What factors promote acceptance? J Telemed Telecare. 2015;21:469-473.

36. Blaiser KM, Behl D, Callow-Heusser C, White KR. Measuring costs and outcomes of Tele-Intervention when serving families of children who are Deaf/Hard-of-Hearing. Int $J$ Telerehabil. 2013;5:3-10.

37. Havenga E, Swanepoel DW, le Roux T, Schmid B. Tele-intervention for children with hearing loss: A comparative pilot study. J Telemed Telecare. 2017;23:116-125. 
38. Tindall LR. Implementation and management of a successful telerehabilitation program in speech language pathology. In: Kumar S, ed. Telerehabilitation. London, England: Springer; 2013:91-100.

39. Meyer C, Scarinci N. Planning a patient- and family-centered approach to service delivery. In: Meyer C, Scarinci N, Hickson L, eds. Patient and Family-Centered SpeechLanguage Pathology and Audiology: Thieme; 2019.

40. Roberts A, Philip L, Currie M, Mort A. Striking a balance between in-person care and the use of eHealth to support the older rural population with chronic pain. Int J Qual Stud Health Well-being. 2015;10: 27536. 
Table 1. Demographics of Family Members Interviewed and Their Children

\begin{tabular}{|c|c|c|c|c|c|c|c|c|c|c|c|}
\hline \multicolumn{6}{|c|}{ Family members $(\mathrm{n}=17)$} & \multicolumn{6}{|c|}{ Children $(n=15)$} \\
\hline ID & Family & $\begin{array}{l}\text { Age } \\
\text { Year }\end{array}$ & Qualification & $\begin{array}{l}\text { Current } \\
\text { Employment }\end{array}$ & $\begin{array}{l}\text { Interview } \\
\text { Type }\end{array}$ & $\begin{array}{l}\text { Age } \\
\text { Month }\end{array}$ & Hearing Loss & $\mathrm{AT}$ & $\begin{array}{l}\text { Other } \\
\text { Dis }\end{array}$ & $\begin{array}{l}\text { Sibling } \\
\text { with } \\
\text { Dis }\end{array}$ & $\begin{array}{l}\text { Living } \\
\text { Area }\end{array}$ \\
\hline$\overline{F 1}$ & Mother & 30 & Postgraduate & $\begin{array}{l}\text { Casual/ part- } \\
\text { time }\end{array}$ & Phone & 19 & B. Mild to Moderate & HA & Yes & No & IRA \\
\hline $\mathrm{F} 2$ & Mother & 31 & High School & Not Working & Phone & 12 & U. Profound & HA & No & No & $\mathrm{MC}$ \\
\hline F16 & Father & 37 & High School & $\begin{array}{l}\text { Casual/ part- } \\
\text { time }\end{array}$ & Phone & “ & “ & “ & “ & “ & “ \\
\hline F3 & Mother & 33 & Undergraduate & $\begin{array}{l}\text { Casual/ part- } \\
\text { time }\end{array}$ & $\begin{array}{l}\text { Face to } \\
\text { Face }\end{array}$ & 14 & B. Mild to Moderate & No & Yes & No & MC \\
\hline $\mathrm{F} 4$ & Mother & 35 & Postgraduate & $\begin{array}{l}\text { Casual/ part- } \\
\text { time }\end{array}$ & Phone & 18 & B. Severe to Profound & CI & No & No & $\mathrm{MC}$ \\
\hline F5 & Mother & 24 & $\begin{array}{l}\text { Not Completed High } \\
\text { School }\end{array}$ & Not Working & Phone & 12 & U. Profound & HA & No & Yes & IRA \\
\hline F6 & Mother & 29 & Undergraduate & Student & Phone & 17 & U. Moderately Severe & HA & Yes & No & $\mathrm{MC}$ \\
\hline F7 & Mother & 34 & Undergraduate & $\begin{array}{l}\text { Casual/ part- } \\
\text { time }\end{array}$ & Phone & 11 & B. Moderately Severe & HA & No & No & $\mathrm{MC}$ \\
\hline F8 & Mother & 40 & High School & Not Working & Phone & 24 & B. Mild to Moderate & HA & No & No & ORA \\
\hline F9 & Mother & 30 & Postgraduate & $\begin{array}{l}\text { Casual/ part- } \\
\text { time }\end{array}$ & Phone & 19 & U. Mild to Moderate & HA & Yes & No & MC \\
\hline F10 & Mother & 26 & High School & Full-time & Phone & 22 & U. Mild & No & No & Yes & ORA \\
\hline F11 & Mother & 33 & Undergraduate & Full-time & Phone & 21 & B. Severe & HA & Yes & No & $\mathrm{MC}$ \\
\hline F12 & Mother & 33 & Diploma & Not Working & Phone & 19 & B. Moderately Severe & HA & Yes & No & $\mathrm{MC}$ \\
\hline F13 & Mother & 38 & Undergraduate & Not Working & Phone & 23 & B. Moderate & HA & Yes & No & ORA \\
\hline F14 & $\begin{array}{l}\text { Grand- } \\
\text { mother }\end{array}$ & 62 & Undergraduate & Not Working & $\begin{array}{l}\text { Face to } \\
\text { Face }\end{array}$ & 24 & B. Profound & $\mathrm{CI}$ & Yes & No & $\mathrm{MC}$ \\
\hline F15 & $\begin{array}{l}\text { Grand- } \\
\text { father }\end{array}$ & 63 & Postgraduate & Not Working & $\begin{array}{l}\text { Face to } \\
\text { Face }\end{array}$ & “ & “" & “ & “ & “" & “ \\
\hline F17 & Father & 35 & High School & Full-time & Phone & 30 & B. Mild to Moderate & HA & No & No & $\mathrm{MC}$ \\
\hline
\end{tabular}


Table 2. Barriers and Facilitators for an eHealth Intervention: Example Quotes from Families and Professionals

\begin{tabular}{|c|c|c|}
\hline $\begin{array}{l}\text { COM-B } \\
\text { Components }\end{array}$ & Category & Example Quote \\
\hline \multicolumn{3}{|l|}{ Capability } \\
\hline \multirow[t]{6}{*}{$\begin{array}{l}\text { Psychological } \\
\text { capability }\end{array}$} & Computer literacy & $\begin{array}{l}\text { I'm not that familiar with doing that [skyping]. [P6] } \\
\text { I'm very good at it [use technology] ... Whatever information I want to have, I just } \\
\text { Google it, I mean I just go online and try to find what can help. [F7] }\end{array}$ \\
\hline & Familiar with social media & $\begin{array}{l}\text { I'm not on Facebook so I don't even know how that works. [P7] } \\
\text { I utilize Facebook groups and things like that. [F9] }\end{array}$ \\
\hline & Being technology Savvy & $\begin{array}{l}\text { I'm not particularly IT savvy so I probably don't follow up on that stuff [online } \\
\text { support] as much as others might. [P7] }\end{array}$ \\
\hline & & My family is quite technology savvy. [F9] \\
\hline & $\begin{array}{l}\text { eHealth is difficult to set up } \\
\text { for professionals }\end{array}$ & $\begin{array}{l}\text { But there's a lot of toing and froing that still happens, before a telehealth session, } \\
\text { that's probably not written to procedures. [P3] } \\
\text { If you've ever been using something like Skype and you're just cutting in and out, } \\
\text { that can be really frustrating. [P8] }\end{array}$ \\
\hline & $\begin{array}{l}\text { Technology is easier for } \\
\text { new clinicians }\end{array}$ & $\begin{array}{l}\text { For newer clinicians, that's easier... for older clinicians or clinicians that have been } \\
\text { in the field a long time, that's more and more difficult to do. [P5] }\end{array}$ \\
\hline \multicolumn{3}{|r|}{ ( } \\
\hline \multirow{8}{*}{$\begin{array}{l}\text { Physical } \\
\text { opportunity }\end{array}$} & Lack of access to the & They [families] don't have the equipment. [P1] \\
\hline & Internet and computer & $\begin{array}{l}\text { My big problem out here was the internet... Here's been atrocious 'cause the } \\
\text { internet is hopeless. [F13] }\end{array}$ \\
\hline & Social media & There's options for like closed groups on social networks. [P5] \\
\hline & & $\begin{array}{l}\text { All of the sudden at home with a baby and that [Facebook] was my only connection } \\
\text { to the outside world sometimes, so connecting. [F11] }\end{array}$ \\
\hline & Smart phones and home & They [families] will have a phone. Generally everyone's got a phone. [P6] \\
\hline & phones & We have phones and iPads, Internet. [F10] \\
\hline & Emails & I'll email if I have permission to email. [P11] \\
\hline & & $\begin{array}{l}\text { It [email] was quite a lot of newsletters and information and newsfeed and stuff [in } \\
\text { emails]. [F17] }\end{array}$ \\
\hline
\end{tabular}




\begin{tabular}{|c|c|c|}
\hline $\begin{array}{l}\text { COM-B } \\
\text { Components }\end{array}$ & Category & Example Quote \\
\hline & $\begin{array}{l}\text { Availability of online } \\
\text { resources and newsletters }\end{array}$ & $\begin{array}{l}\text { We also send out a bulletin/newsletter three times a year to families to talk about and } \\
\text { we have bits of information in that and web links in it that they can go and access } \\
\text { information to as well. [P5] } \\
\text { They [Parent Support Group] sent an email for all that sorts of stuff. There's lots of } \\
\text { newsletters and stuff. [F17] }\end{array}$ \\
\hline & $\begin{array}{l}\text { Online training for } \\
\text { professionals and families }\end{array}$ & $\begin{array}{l}\text { There's so many of them [online training]. They just pop up again and you've got to } \\
\text { do them. [P7] } \\
\text { We can do the classes from home ... do online training as well. [F13] }\end{array}$ \\
\hline & $\begin{array}{l}\text { Availability of iPad loan } \\
\text { scheme and }\end{array}$ & $\begin{array}{l}\text { We also have a Telehealth service, so an iPad loan service goes along with that. So, } \\
\text { we Skype with parents if they're wherever really. [P2] }\end{array}$ \\
\hline & videoconferencing & She [P] was saying that they set up Skype meetings with some people. [F3] \\
\hline & Availability of electricity & $\begin{array}{l}\text { They [family] don't actually have electricity so often the mobile phone is not charged } \\
\text { because it's only charged when they drive somewhere ... Now the thing is this family } \\
\text { doesn't have electricity ... They have a generator and a trans evidently, so obviously } \\
\text { teleschool, telepractice you name it is not going to be very useful to them. These } \\
\text { children do not have any communication system. [P1] }\end{array}$ \\
\hline & $\begin{array}{l}\text { Availability of informative } \\
\text { DVDs and DVD players }\end{array}$ & $\begin{array}{l}\text { We have a couple of DVDs and one of them is about communicating with your } \\
\text { baby... something that we provide to all parents is that DVD. [P2] } \\
\text { I didn't have a DVD [player], that machine. [F7] }\end{array}$ \\
\hline & $\begin{array}{l}\text { Availability of an app for } \\
\text { information, making } \\
\text { appointments, and storing }\end{array}$ & $\begin{array}{l}\text { We've just developed an app for parents so we give them a flyer in the kit about that } \\
\text { so they can download that if they want to... It also gives them the opportunity to } \\
\text { make appointments and request calls, store documents. [P2] }\end{array}$ \\
\hline & documents & I did ask [P] try to find out which one was it [app]. Finally I got it. [F7] \\
\hline & Affordability & $\begin{array}{l}\text { Just financially able to have a laptop in the house. You know, that's not a cheap } \\
\text { item. [P6] }\end{array}$ \\
\hline & & For some of them [families] Internet maybe not affordable. [P1] \\
\hline & Voice constraints & $\begin{array}{l}\text { I think there's some voice constraints with it, so similar to a telephone, you have to } \\
\text { talk straight into it and while you can see each other's facial expressions ... so } \\
\text { volumes an issue, so people feel, and sometimes it's necessary for them to speak up. } \\
\text { [P3] }\end{array}$ \\
\hline
\end{tabular}




\begin{tabular}{|c|c|c|}
\hline $\begin{array}{l}\text { COM-B } \\
\text { Components }\end{array}$ & Category & Example Quote \\
\hline \multirow[t]{4}{*}{$\begin{array}{l}\text { Social } \\
\text { opportunity }\end{array}$} & Face-to-face culture & $\begin{array}{l}\text { Most of my career has been in face-to-face counselling so I guess I have a } \\
\text { professional background of being in a face-to-face environment with people. [P7] } \\
\text { If you've got workers that have been working in a particular way, that's face-to-face } \\
\text { like we're doing now and you're asking them to all of a sudden have confidence in } \\
\text { electronic technology to do Telehealth ... you actually are talking about bringing } \\
\text { about a culture change within your professional clinicians. [P5] }\end{array}$ \\
\hline & $\begin{array}{l}\text { Encouraging } \\
\text { videoconferencing }\end{array}$ & $\begin{array}{l}\text { In the office, it's generally, it's encouraged and accepted if you want to do that } \\
\text { [videoconferencing]. [P6] }\end{array}$ \\
\hline & $\begin{array}{l}\text { More tendency to use } \\
\text { technology among younger } \\
\text { families }\end{array}$ & $\begin{array}{l}\text { Some of those young ones are really up with just using iMessages and stuff. You } \\
\text { could use FaceTime because they're used to it. [P4] }\end{array}$ \\
\hline & $\begin{array}{l}\text { A registered parent-to- } \\
\text { parent program to facilitate } \\
\text { connecting families of the } \\
\text { same culture }\end{array}$ & $\begin{array}{l}\text { I'm wondering if there's a way that you could have like a register families within our } \\
\text { services that want to meet up with other families of a similar language group, similar } \\
\text { cultures, similar country. Because That takes a lot of work for us. Then we got, oh } \\
\text { okay, this has I got a family, and they will contact your families, they all come back, } \\
\text { but sometimes, I don't know, maybe that's something like a register and you just put } \\
\text { your name down. [P6] }\end{array}$ \\
\hline \multicolumn{3}{|r|}{ (20) } \\
\hline \multirow[t]{2}{*}{$\begin{array}{l}\text { Automatic } \\
\text { motivation }\end{array}$} & $\begin{array}{l}\text { Routine use phone calls, } \\
\text { mobiles, and emails }\end{array}$ & $\begin{array}{l}\text { I'm happy just to phone call once we've got a visual of each other. [P6] } \\
\text { I'd be lost without my phone; I'd be lost without Facebook. [F5] }\end{array}$ \\
\hline & $\begin{array}{l}\text { Families do not check their } \\
\text { emails }\end{array}$ & Half the time I forget that emails are even there, don't check it very often. [F1] \\
\hline \multirow[t]{3}{*}{$\begin{array}{l}\text { Reflective } \\
\text { motivation }\end{array}$} & $\begin{array}{l}\text { Families prefer to access } \\
\text { online information and } \\
\text { reminders }\end{array}$ & $\begin{array}{l}\text { These days you're so busy, you get the letter a month before, and you tend to forget } \\
\text { when the appointment is. Yeah, when you get these reminders it's pretty handy, and } \\
\text { it's easy as well, so that's good. [F16] }\end{array}$ \\
\hline & $\begin{array}{l}\text { Some families prefer phone } \\
\text { calls }\end{array}$ & $\begin{array}{l}\text { They [families] are not interested [in videoconferencing]. They're happy to just talk } \\
\text { on the phone. [P9] }\end{array}$ \\
\hline & & $\begin{array}{l}\text { I think I prefer people to phone me about things and then that way we're both getting } \\
\text { our points across. Instead of sending } 50 \text { million emails to try and get one point } \\
\text { across, and not get offended, because you don't know what kind of, how to take the }\end{array}$ \\
\hline
\end{tabular}




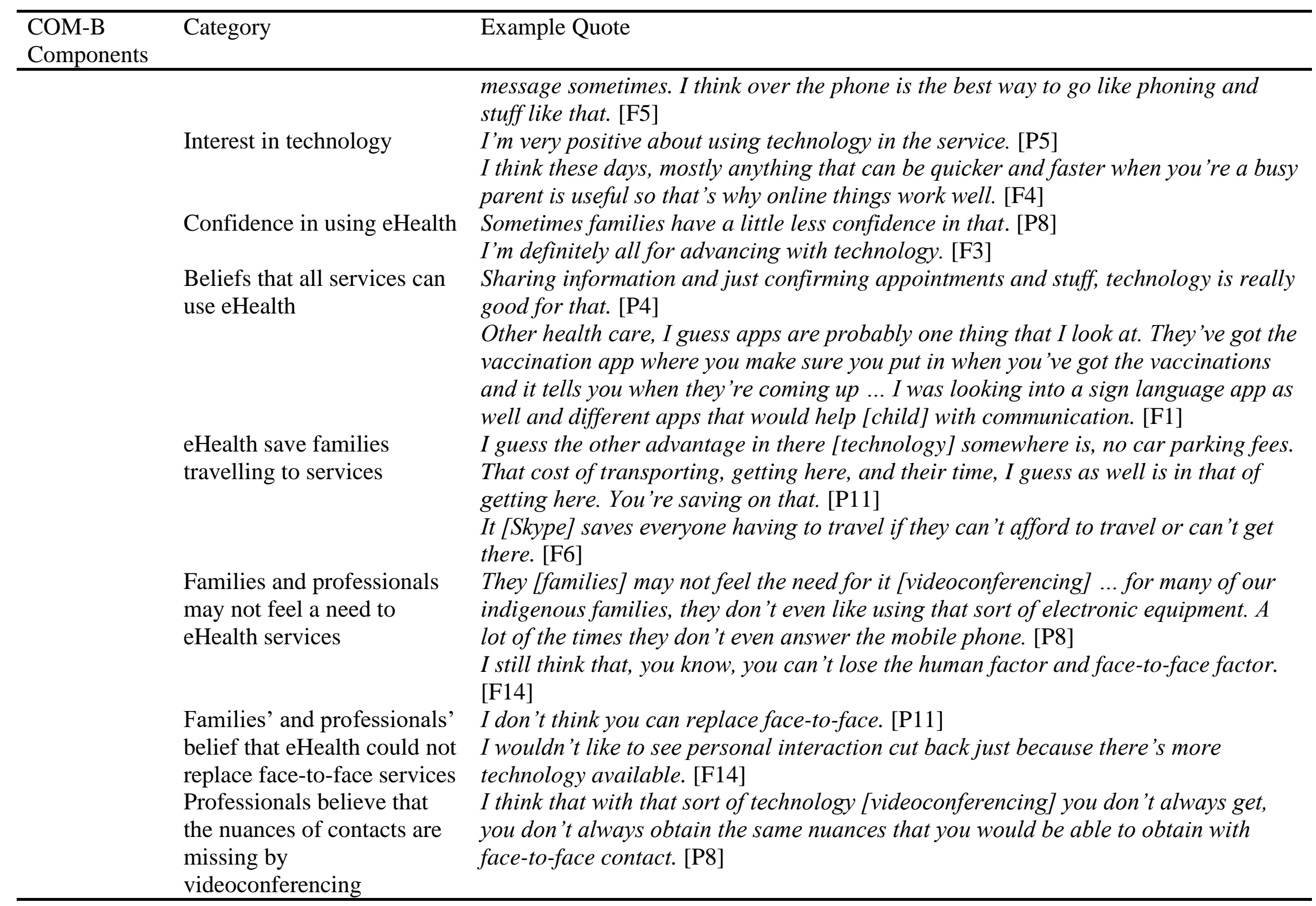




\begin{tabular}{|c|c|c|}
\hline $\begin{array}{l}\text { COM-B } \\
\text { Components }\end{array}$ & Category & Example Quote \\
\hline & & $\begin{array}{l}\text { There's an additional component to a face-to-face service that's not really fulfilled } \\
\text { by that kind of technology. [P2] }\end{array}$ \\
\hline & $\begin{array}{l}\text { Telecommunication is not a } \\
\text { preferred mode of }\end{array}$ & $\begin{array}{l}\text { I think it [telehealth] is a great adjunct; I would hate to see that it becomes the main } \\
\text { form of communication with families. [P8] }\end{array}$ \\
\hline & $\begin{array}{l}\text { communication but } \\
\text { complementary }\end{array}$ & I think they [face-to-face and eHealth] are complementary. [P5] \\
\hline & Connectivity & $\begin{array}{l}\text { That has been some of the issues is technology trying linking trying to maintain } \\
\text { connection. [P10] }\end{array}$ \\
\hline
\end{tabular}

Note. P: professional; F: family member. 